\title{
Design simulation and economic optimization of a benzene-toluene-xylene system distillation process upon the energy cost
}

\author{
S. Silviana ${ }^{1 *}$, Febio Dalanta ${ }^{2}$, Dewi Qurrota A'yuni ${ }^{2}$, Lu'luatul Khoiriyah ${ }^{2}$, Putri Rousan \\ Nabila $^{2}$ and M. Fahrizal Alfaris ${ }^{2}$ \\ ${ }^{1}$ Department of Chemical Engineering, Faculty of Engineering, Diponegoro University, Jl. Prof. \\ Soedarto, SH, Semarang, 50275, Indonesia \\ ${ }^{2}$ Master Program, Department of Chemical Engineering, Faculty of Engineering, Diponegoro \\ University, Jl. Prof. Soedarto, SH, Semarang, 50275, Indonesia
}

\begin{abstract}
Distillation is the most extensively used in separation process of the chemical industry. Relationships between non-linear variables, multivariable interactions, dynamic system properties, and other irregularities render the study of design simulation and process optimization an interesting challenge for process engineers. The objective of the process optimization is to produce the most economical to conduct the system. This paper discusses the process engineering strategy started from the determination method of the degree of freedom, design variables, process tools, economic parameters, and the optimization process. The distillation variable optimized in this study was limited to reflux ratio. The optimum variable was construed from the reflux ratio producing the lowest total annual cost (TAC). Furthermore, it was analyzed the energy cost as optimization parameter in the total annual cost (TAC) calculation method to obtain minimum reflux ratio in distillation unit.
\end{abstract}

\section{Introduction}

\subsection{Background}

Distillation plays a substantial contribution towards a chemical factory. Distillation is a very common method of separation employed in the chemical industry and presents complex process in its modelling and control $[1,2]$. The distillation columns are employed in many separation process of the chemical industry [3], whereby control is needed to obtain products with a specified purity at minimum cost. This is by all means very difficult to achieve due to the presence of process irregularities, multivariable interactions, dynamic system properties and microscopic disturbances in the distillation column [4]. More specifically, the continuous distillation exhibits very dynamic properties during a process. A distillation process is based upon the vapour-liquid equilibrium. Distillation can be used to separate chemical components

* Corresponding author: silviana@che.undip.ac.id 
that settle at different concentrations at the two different phases. Using the principles of mass transfer and heat transfer, processes in the distillation column can be simulated/modelled.

Dwekar et al (1989) studied multivariable optimization in a distillation column, and produced formulas for single-fraction distillation and multi-fraction batch distillation under constant operating conditions and reflux ratio [5]. Ren et al (2010) presented a model of the stages in the distillation column to optimize the reflux ratio by resolving the nonlinear objective function of the design [6]. Optimization of the propane-propylene system distillation has been figured out by Mauhar et al (2004) applying simulation software of Aspen Plus [7]. An approach that produces pressure value and reflux ratio to minimize energy duty of the reboiler and produce product assigning to the standard.

The operating conditions of a petroleum refinery column have been optimized by using a tool to minimize energy consumption [8]. This simulation result at a later stage was successfully applied to the pilot plant unit [8]. Earlier optimizations of two distillation columns have been carried out using reflux ratio variable in a petroleum refinery facility [9].

Economic design calculations are very important in an industrial design. Optimization processes of distillation columns have been carried out in previous literatures to compute a minimum Total Annual Cost. In this simulation, optimization of a three components distillation process has been carried out by using a variation of the reflux ratio to designate the lowest annual operating costs. In general, the stages of this simulation are include the illustration of processes, analysis of degree of freedom and design variables, compilation of calculation algorithms, modelling, and simulations using MATLAB, Ms. Excel, and Polymath software to discern the optimum reflux ratio value.

\subsection{Case Study}

Distillation columns constructed in a series are used to separate components contained in the feed comprised of $30 \%$ benzene, $55 \%$ toluene and $15 \%$ xylene. The first column distillate is expected to generate $94.4 \%$ benzene, $4.54 \%$ toluene, and $1.06 \%$ xylene. The second column is designed to recover $92 \%$ of the toluene from the incoming feed, through which analysis showed a composition of $94.6 \%$ toluene. Additionally, the bottom of the second column is expected to recover $92.6 \%$ xylene making up $77.6 \%$ of the whole composition. Feed enters under saturated liquid conditions at a pressure of $1 \mathrm{~atm}$. The detail of process is displayed in Figure 1.

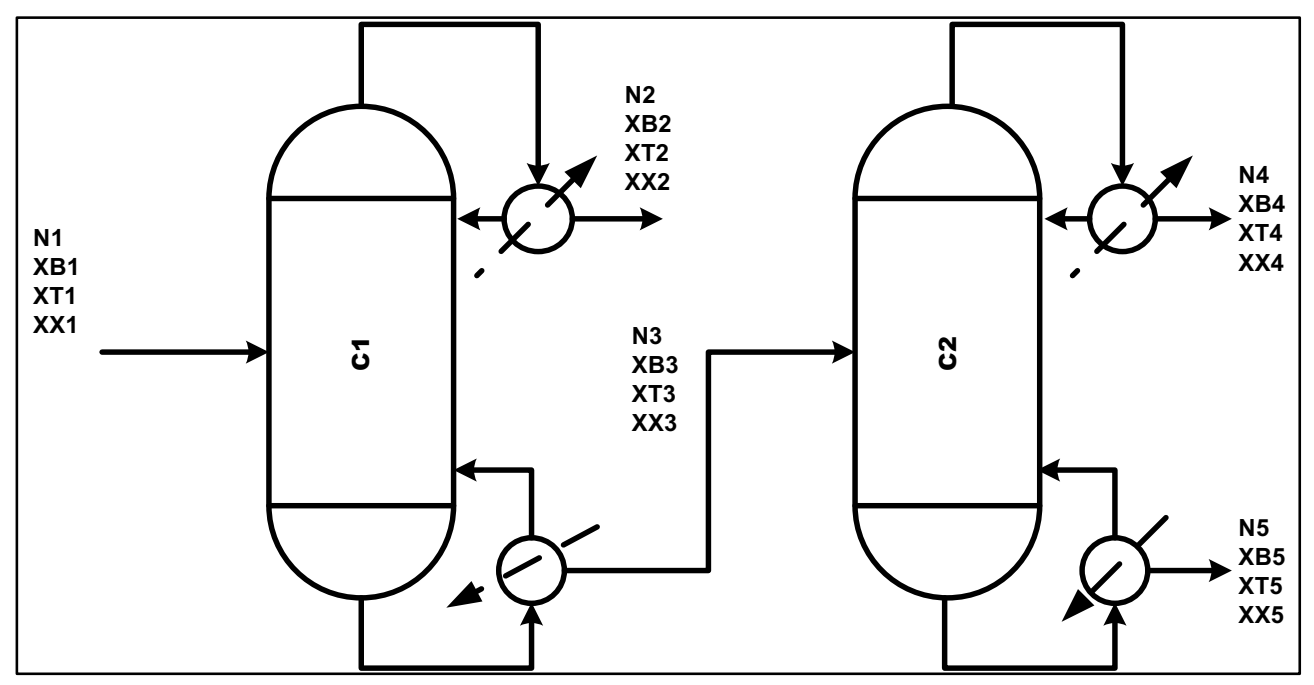


Fig. 1. Distillation Process Scheme [10].

\subsection{Aims}

This paper goals are referred to identify the degree of freedom and design variables of the system, to generate a system design model, to analyse reflux ratio with the lowest total operating cost/TAC

\section{Discussion}

\subsection{Analysis of Degree of Freedom of the System}

Analysis of degree of freedom is needed to determine the characteristics of a system and the number of design variables needed to settle the flow of information into a defined variable system. The method of determining the degree of freedom of the system refers to the book Strategy of process engineering [11]. In the present discussion, the analysis of degree of freedom is carried out in three different approaches with the aim of ensuring the accuracy of the analysis of degree of freedom performed. Analysis of the degree of freedom of the system can be done through the following three methods:

(1) Calculation from the relationship between the number of variables minus the available free equation

(2) Calculation from a holistic review of the system

(3) Calculation from the relationship between the local degree of freedom of each sub-system and the existing local degree of freedom

\subsubsection{Analysis of degree of freedom with method (1)}

Calculation of the degree of freedom with this method requires the overall number of variables and the number of variables in the system [11]. The information flow of each variable in this distillation system can be seen in Figure 2 .

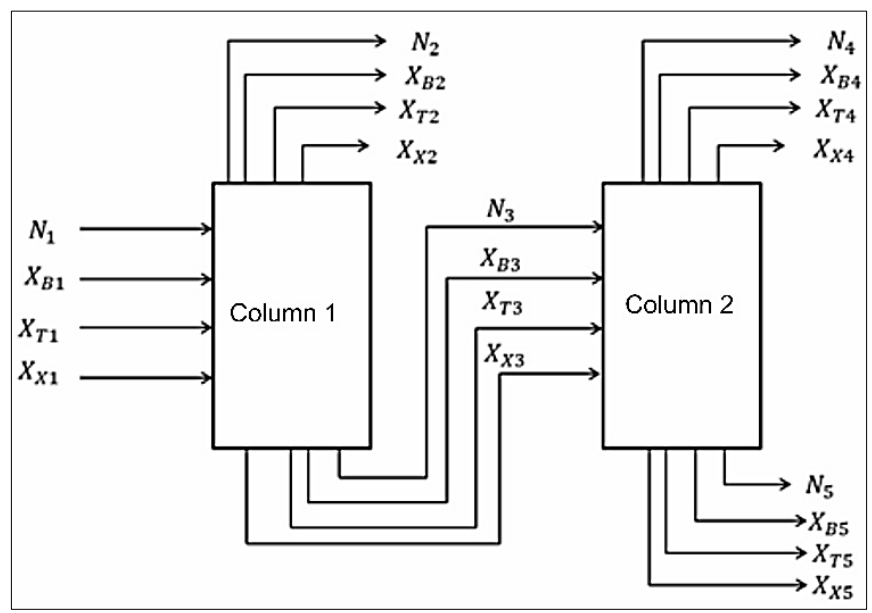

Fig. 2. Distillation tower system information flow. 
Variables information can be seen in Table 1 and the equations expressing the relationship between variables in the system can be seen in Table 2.

Table 1. List of known variable values and conditions.

\begin{tabular}{llll}
\hline Sub system & No & Variable & Description \\
& & & \\
& 1 & $X_{B 2}=0.9440$ & Column 1 top product \\
Column 1 & 3 & $X_{T 2}=0.0454$ & Column 1 top product \\
& 4 & $X_{X 1}=0.0106$ & Column 1 top product \\
& 5 & $X_{T 1}=0.30$ & Column 1 feed \\
& 6 & $X_{X 1}=0.15$ & Column 1 feed \\
Column 2 & 7 & $X_{T 4}=0.946$ & Column 1 feed \\
& 8 & $X_{X 5}=0.776$ & Column 2 top product \\
& 9 & $N_{4} X_{T 4}=(0.92) N_{I} X_{T 1}$ & Column 2 top product \\
& 10 & $N_{5} X_{X 5}=(0.926) N_{I} X_{X 1}$ & Output specification \\
\hline
\end{tabular}

Table 2. List of equations and variables.

\begin{tabular}{|c|c|c|c|}
\hline $\begin{array}{l}\text { System } \\
\text { no. }\end{array}$ & Equation & $\begin{array}{c}\text { Unknown } \\
\text { variable(s) }\end{array}$ & Description \\
\hline 1 & $N_{1}=N_{2}+N_{3}$ & 3 & Total mass balance in column 1 \\
\hline 2 & $N_{1} X_{T 1}=N_{2} X_{T 2}+N_{3} X_{T 3}$ & 1 & $\begin{array}{l}\text { Mass balance of toluene } \\
\text { component in column } 1\end{array}$ \\
\hline 3 & $N_{1} X_{X 1}=N_{2} X_{X 2}+N_{3} X_{X 3}$ & 1 & $\begin{array}{l}\text { Mass balance of xylene } \\
\text { component in column } 1\end{array}$ \\
\hline 4 & $N_{3}=N_{4}+N_{5}$ & 2 & Total mass balance in column 2 \\
\hline 5 & $N_{3} X_{T 3}=N_{4} X_{T 4}+N_{5} X_{T 5}$ & 1 & $\begin{array}{l}\text { Mass balance of toluene } \\
\text { component in column } 2\end{array}$ \\
\hline 6 & $N_{3} X_{X 3}=N_{4} X_{X 4}+N_{5} X_{X 5}$ & 1 & $\begin{array}{l}\text { Mass balance of xylene } \\
\text { component in column } 2\end{array}$ \\
\hline 7 & $N_{4} X_{T 4}=0.92 X_{T 1} N_{1}$ & 0 & Recovery \\
\hline 8 & $N_{5} X_{5}=0.926 X_{X 1} N_{1}$ & 0 & Recovery \\
\hline
\end{tabular}

With the data above, determining the degree of freedom can be done as follows.

Number of Equations $(N)=8$

Number of Variables $(M)=9\left(N_{i}, N_{2}, N_{s}, X_{*}, X_{*}, N_{4}, N_{s}, X_{\bar{*}}, X_{* s}\right)$

Degree of freedom $\quad=M-N$

$$
=9-8=1
$$

The degree of freedom of this system calculated based on all variables and related equations is 1 .

\subsubsection{Analysis of degree of freedom with method (2)}

This calculation method is done by reviewing the overall system through the mass flow of components in and out of the system. The specific information on the variables and related equations of this method can be seen in Table 3 .

The degree of freedom of this system is calculated using 1 variable and all related equations.

Number of equations $(\mathrm{N}) \quad=5$

Number of variables $(M)=6\left(N_{1}, N_{2}, N_{4}, N_{s}, X_{r s}, X_{x^{4}}\right)$ 
Degree of freedom $\quad=\mathrm{M}-\mathrm{N}=6-5=1$

The degree of freedom of this system calculated based on all variables and related equations is 1 same as the one obtained in method (1).

Table 3. List of equations and variables of the overall system.

\begin{tabular}{|c|c|c|c|c|}
\hline No & Equation & $\begin{array}{l}\text { Number of } \\
\text { variable(s) }\end{array}$ & Description & \\
\hline 1 & $N_{l}=N_{2}+N_{4}+N_{5}$ & 4 & Total mass balance & \\
\hline 2 & $\begin{array}{l}N_{1} X_{T 1}=N_{2} X_{T 2}+N_{4} X_{T 4}+ \\
N_{5} X_{T 5}\end{array}$ & 1 & $\begin{array}{l}\text { Mass balance of the } \\
\text { component }\end{array}$ & toluene \\
\hline 3 & $\begin{array}{l}N_{1} X_{X 1}=N_{2} X_{X 2}+N_{4} X_{X 4}+ \\
N_{5} X_{X 5}\end{array}$ & 1 & $\begin{array}{l}\text { Mass balance of the } \\
\text { component }\end{array}$ & xylene \\
\hline 4 & $N X_{T 4}=0,92 X_{T I} N_{l}$ & 0 & Recovery & \\
\hline 5 & $N X_{X 5}=0,926 X_{X I} N_{1}$ & 0 & Recovery & \\
\hline
\end{tabular}

\subsubsection{Analysis of degree of freedom with method (3)}

The degree of freedom in this method is calculated from the relationship of the local degree of freedom of each sub-system and the existing local degree of freedom. The variables information flow in subsystem 1 can be seen in Figure 3 and subsystem 2 in Figure 4.

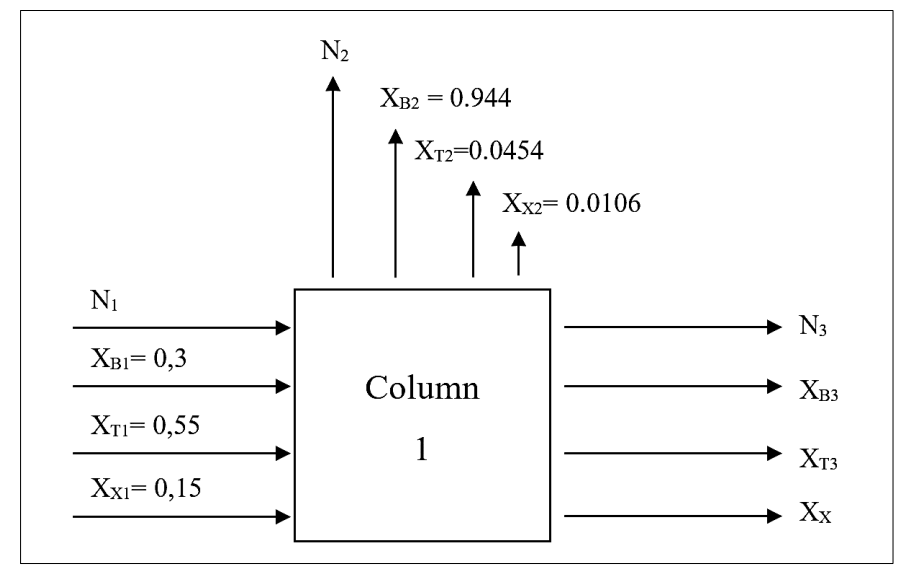

Fig. 3. First column distillation tower system information flow.

Applied equations:

Number of equations $(N)$

$$
\begin{aligned}
& N_{t}=N_{2}+N_{3} \\
& N_{1} X_{1}=N_{2} X_{72}+N_{:} X_{B s} \\
& N_{1} X_{x l}=N_{2} X_{x 2}+N_{3} X_{x s} \\
& N_{1} X_{B 1}=N_{2} X_{B 2}+N_{3} X_{B 3} \\
& \text { Number of variables }(M)=5\left(N_{1}, N_{2}, N_{s}, X_{s}, X_{x s}\right) \\
& =4 \\
& =M-N=5-4=1
\end{aligned}
$$$$
\text { Degree of freedom }
$$ 


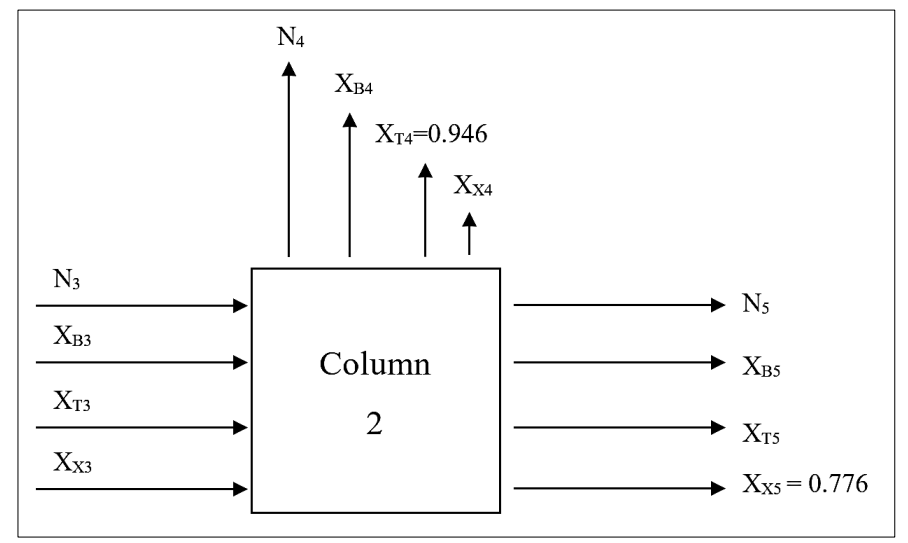

Fig. 4. Second column distillation tower system information flow.

Applied equations:

$$
\begin{gathered}
N_{3}=N_{4}+N_{5} \\
N_{3} X_{T 3}=N_{4} X_{T 4}+N_{5} X_{T 5} \\
N_{3} X_{X 3}=N_{4} X_{X 4}+N_{5} X_{X 5} \\
N_{3} X_{B 3}=N_{4} X_{B 4}+N_{5} X_{B 5} \\
N_{4} X_{T 4}=0.92 N_{1} X_{T 1} \\
N_{5} X_{5}=0.926 N_{1} X_{X 1}
\end{gathered}
$$

Local degrees of freedom $=M-N=10-6=4$

With connecting variables of $N_{3}, X_{B 3}, X_{T 3}, X_{X 3}$

DoF $=(1+4)-($ connecting variables $)$

$$
=(1+4)-(4)=1
$$

The degree of freedom of the system calculated in this method is 1 . The result is the same as the value obtained in methods (1) and (2), and thus the analysis of degrees of freedom in this case is conclusively valid.

\subsubsection{Determination of Design Variables and System Calculation Algorithm}

The analysis of degree of freedom of the system obtained a value of 1 , meaning that the number of design variables in this system is 1 . Determination of the design variable employs the structural array method cited from the book Strategy of process engineering [11]. The variable elimination method is illustrated in Figure 5. Through the structural array elimination, the non-eliminated variable found is $N_{t}$. Therefore, the design variable involved in this case is $N$, denoting the feed molar flow rate that enters the distillation column. In this system there is no recycling flow parameter.

State variable can be deliberated as follows (based on Table 2)

$N_{s}$ calculated from equation (8)

$N$ calculated from equation (7)

$N_{3}$ calculated from equation (4)

$N_{2}$ calculated from equation (1)

$X_{x s}$ calculated from equation (3)

$X_{x \neq}$ calculated from equation (6)

$X_{T S}$ calculated from equation (5) 


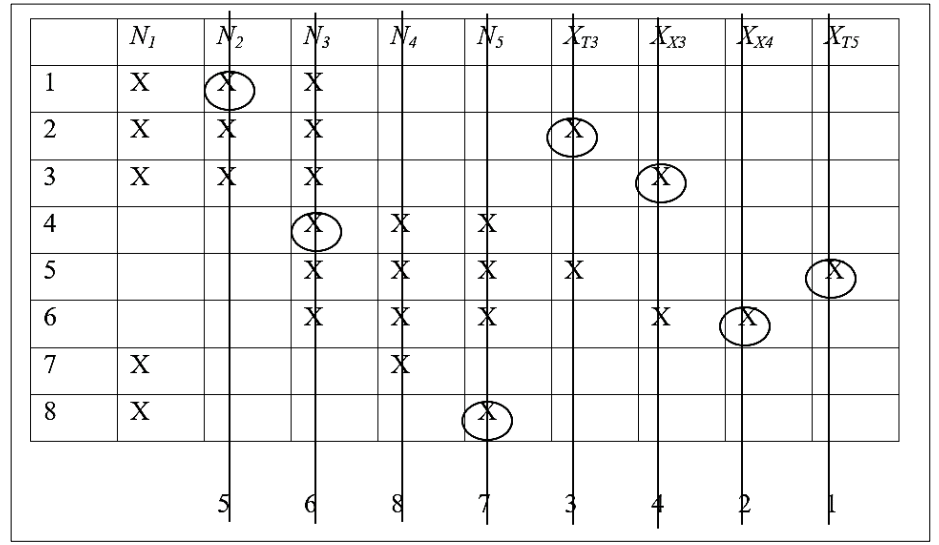

Fig. 5. Structural array in design variables determination based on equations in Table 2 .

The non-eliminated variable is $N$, placing the feed molar flow rate as the design variable of this distillation column design. The system calculation algorithm that expresses the process of defining each state variable in this particular case can be seen in Figure 6.

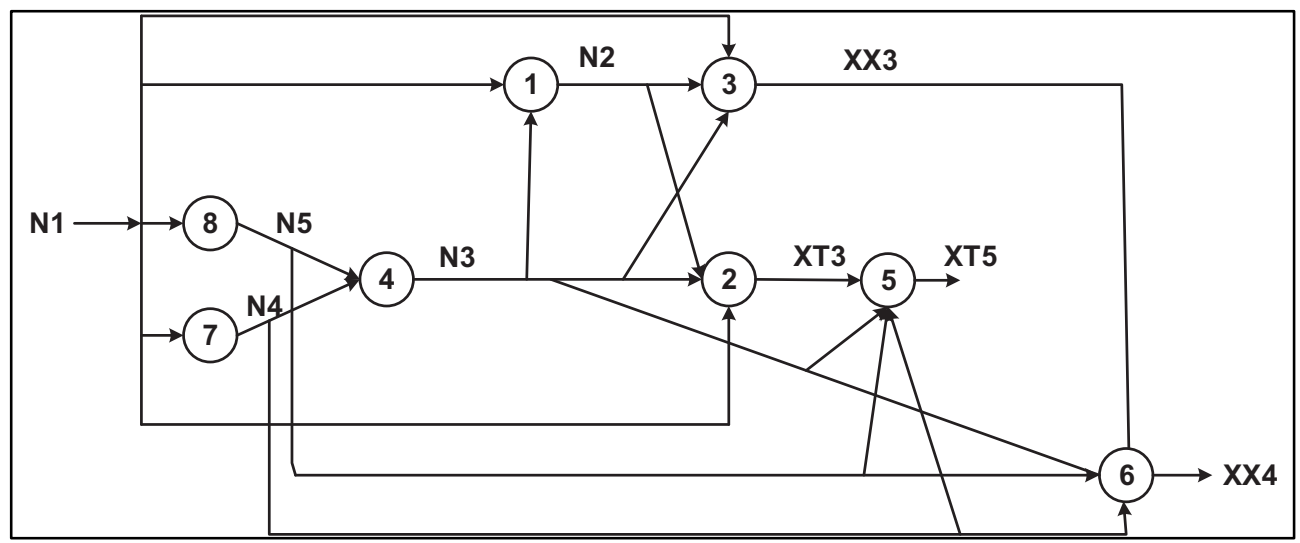

Fig. 6. System calculation algorithm.

\subsection{System Design Model}

\subsubsection{Mass Flow and Composition}

The design of the system outsets from the calculation of unknown values using the design equations compiled in section 2.1. The calculation of the value of unknown variables employs the Polymath software with Non-linear equations solver. The equation models are listed in Figure 7. Calculation results are presented in Figure 8. 
\#Nonlinear equations solver by Polymath\#

$\mathrm{N} 1=100$ \#Molar flowrate of feed $(\mathrm{mol} / \mathrm{h})$-> Design variable

$\mathrm{XB1}=0.3$ \#Composition of benzene in feed

$\mathrm{XT} 1=0.55$ \#Composition of toluene in feed

$X X 1=0.15$ \#Composition of xylene in feed

$\mathrm{XB2}=0.944$ \#Composition of benzene in top product of column 1

$\mathrm{XT} 2=0.0454$ \#Composition of toluene in top product of column 1

$\mathrm{XX} 2=0.0106$ \#Composition of benzene in top product of column 1

XT4 $=0.946$ \#Composition of toluene in in top product of column 2

$\mathrm{XX5}=0.776$ \#Composition of xylene in bottom product of column 2

$\mathrm{N} 4=\left(0.92 * \mathrm{~N} 1{ }^{*} \mathrm{XT} 1\right) / \mathrm{XT} 4$ \#Molar flowrate of distillate of column $2(\mathrm{~mol} / \mathrm{h})$

$\mathrm{N} 3=\mathrm{N} 4+\mathrm{N} 5$ \#Molar flowrate of bottom product of column 1 (mol/h)

$\mathrm{N} 5=\left(0.926^{*} \mathrm{XX} 1{ }^{*} \mathrm{~N} 1\right) / \mathrm{XX} 5$ \#Molar flowrate of bottom product of column $2(\mathrm{~mol} / \mathrm{h})$

$\mathrm{N} 2=\mathrm{N} 1-\mathrm{N} 3$ \#Molar flowrate of distillate of column $1(\mathrm{~mol} / \mathrm{h})$

$\mathrm{XT} 3=\left(\mathrm{N} 1{ }^{*} \mathrm{XT} 1-\mathrm{N} 2{ }^{*} \mathrm{XT} 2\right) / \mathrm{N} 3$ \#Composition of toluene in bottom product of column 1

$\mathrm{XX} 3=\left(\mathrm{N} 1{ }^{*} \mathrm{XX} 1-\mathrm{N} 2{ }^{*} \mathrm{XX} 2\right) / \mathrm{N} 3$ \#Composition of xylene in bottom product of column 1

$\mathrm{XB3}=1-\mathrm{XX} 3-\mathrm{XT} 3$ \#Composition of benzene in bottom product of column 1

$\mathrm{XX} 4=\left(\mathrm{N} 3{ }^{*} \mathrm{XX} 3-\mathrm{N} 5 * \mathrm{XX} 5\right) / \mathrm{N} 4$ \#Composition of xylene in top product of column 2

$\mathrm{XB} 4=1-\mathrm{XX} 4-\mathrm{XT} 4$ \#Composition of xylene in top product of column 2

$\mathrm{XT5}=\left(\mathrm{N} 3{ }^{*} \mathrm{XT} 3-\mathrm{N} 4{ }^{*} \mathrm{XT} 4\right) / \mathrm{N} 5$ \#Composition of toluene in bottom product of column 2

XB5=1-XT5-XX5 \#Composition of benzene in bottom product of column 2

Fig. 7. System nonlinear equation model.

\begin{tabular}{|c|c|c|c|}
\hline \multicolumn{3}{|c|}{$\begin{array}{l}\text { POLYMATH Report } \\
\text { Explicit Equations }\end{array}$} & $\begin{array}{r}\text { No Title } \\
\text { 15-Apr-2020 }\end{array}$ \\
\hline \multicolumn{4}{|c|}{ Calculated values of explicit variables } \\
\hline & Variable & Value & \\
\hline 1 & N1 & 100. & \\
\hline 2 & N2 & 28.61214 & \\
\hline 3 & N3 & 71.38786 & \\
\hline 4 & N4 & 53.48837 & \\
\hline 5 & N5 & 17.89948 & \\
\hline 6 & XB1 & 0.3 & \\
\hline 7 & XB2 & 0.944 & \\
\hline 8 & XB3 & 0.0418858 & \\
\hline 9 & XB4 & 0.038918 & \\
\hline 10 & XB5 & 0.0507543 & \\
\hline 11 & $\mathrm{XT} 1$ & 0.55 & \\
\hline 12 & $\mathrm{XT} 2$ & 0.0454 & \\
\hline 13 & $3 \mathrm{XT} 3$ & 0.7522429 & \\
\hline 14 & XT4 & 0.946 & \\
\hline 15 & $5 \mathrm{XT5}$ & 0.1732457 & \\
\hline 16 & $\mathrm{XX1}$ & 0.15 & \\
\hline 17 & $x \times 2$ & 0.0106 & \\
\hline 18 & $3 \times 3$ & 0.2058713 & \\
\hline 19 & $x \times 4$ & 0.015082 & \\
\hline 20 & $x \times 5$ & 0.776 & \\
\hline
\end{tabular}

Fig. 8. Distillation system calculation results.

The results in Figure 8 can be assigned onto the distillation process scheme to facilitate the design of the column series. The resulting scheme can be seen in Figure 9. 


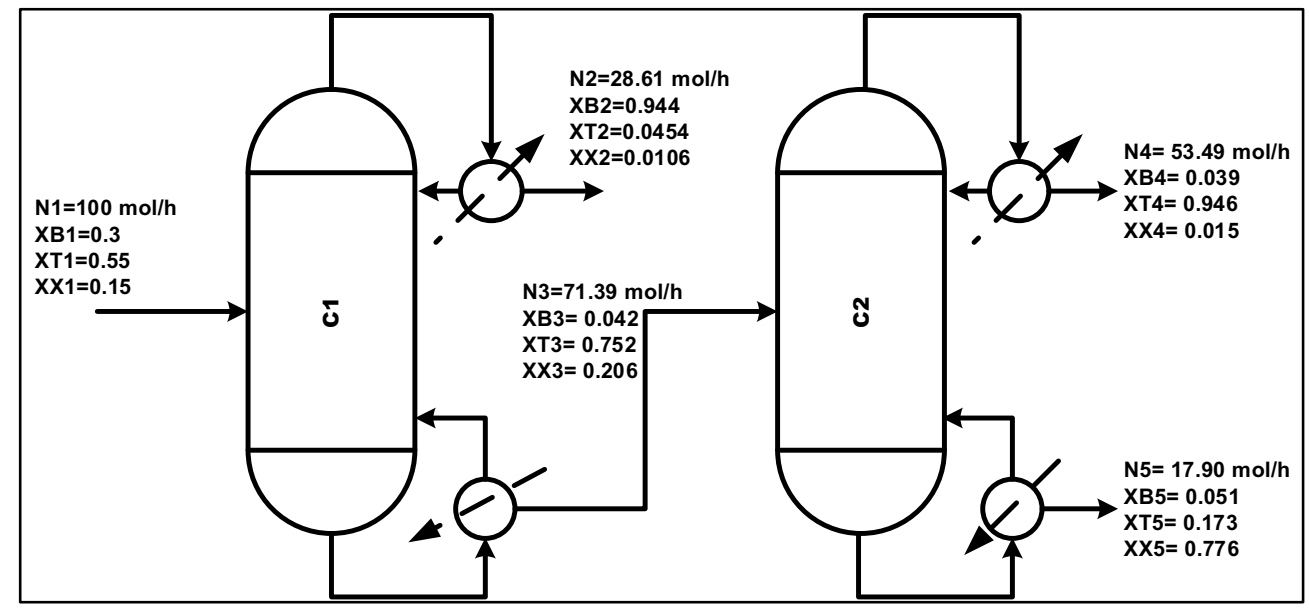

Fig. 9. Complete scheme of mass flow and composition in the distillation column.

\subsubsection{Distillation Column Design}

All data relating to the mass flow and composition in this distillation sequence system are generated. In this section, a simulation of reflux ratio in relations to profitability parameters is made since the relationships between reflux ratio and certain parameters tend to be nonlinear and in opposition to one another. Accordingly, to acquire the reflux ratio conditions that result in the highest profitability, it is necessary to simulate and optimize the process.

a) Method

The distillation column design in this case study incorporates the Mc-Cabe-Thiele model. Several assumptions were used in the design of this column:

1. The flow rate between vapour and liquid along the column is constant (constant molar overflow) as is the relative volatility

2. Latent heat evaporation is assumed to be the same at all times and all compositions in each tray

3. The distillation system does not experience foaming

4. Total condenser and partial reboiler are applied

5. The first and second distillation columns have the same operating conditions and types

The design procedure is simulated using Ms. Excel and MATLAB with the following steps:

1. Employment of all data on the multicomponent system vapour-liquid equilibrium curves;

2. Collection of thermodynamic data of benzene, toluene, and xylene;

3. Calculation of the flow rate in and out of the column;

4. Calculation of the value of the minimum reflux ratio and the minimum number of trays;

5. Calculation of the loads of the reboiler and condenser;

6. Calculation of the maximum and minimum values of vapour and liquid flow in a column;

7. Iteration to get a balanced composition;

8. Calculation of plate layout, diameter and column height values;

9. Calculation of the pressure drop;

10. Reiteration for stage/plate/tray values that are too small or too large; 
11. Determining the relationship between different reflux ratio of tray, feed tray location, tray diameter, column height, condenser load, reboiler load, condenser area and reboiler area.

b) Design outcome

Through a calculation simulation the influence of the reflux ratio on the distillation column design parameters is obtained. Sample results from the simulation relating the number of plates can be seen in Figure 10 and the overall results of the design and simulation of the distillation column by using MATLAB can be seen in Table 4.

Table 4. Reflux ratio simulation results on column design.

\begin{tabular}{lrrrrrr}
\hline Reflux ratio & $\mathbf{1}$ & $\mathbf{1 . 2}$ & $\mathbf{1 . 5}$ & $\mathbf{2}$ & $\mathbf{3}$ & $\mathbf{5}$ \\
\hline Number of plates & 13 & 9 & 7 & 6 & 5 & 5 \\
Feed plate location & 7 & 5 & 4 & 4 & 4 & 3 \\
Column diameter (m) & 8.59 & 9.42 & 9.87 & 10.11 & 10.35 & 10.35 \\
Column height (m) & 31.20 & 21.60 & 16.80 & 14.40 & 12.00 & 12.00 \\
Condenser load (MW) & 35.79 & 49.95 & 57.87 & 62.04 & 66.35 & 66.35 \\
Reboiler load (MW) & 25.53 & 33.21 & 37.41 & 39.60 & 41.85 & 41.85 \\
Condenser surface area $\left(\mathrm{m}^{2}\right)$ & 302.21 & 421.78 & 488.65 & 523.86 & 560.26 & 560.26 \\
Reboiler surface area $\left(\mathrm{m}^{2}\right)$ & 129.17 & 168.02 & 189.26 & 200.34 & 211.73 & 211.73 \\
\hline
\end{tabular}

\begin{tabular}{|llr|}
\hline Parameters & F & $0.1 \mathrm{kmol} \mathrm{h}^{2}$ \\
Feed Flowrate & xF & $0.3 \mathrm{~mol} \mathrm{frac}$ \\
Feed Frac Light Component & xD & $0.944 \mathrm{~mol} \mathrm{frac}$ \\
Top Prod Frac Light Component & xW & $0.042 \mathrm{~mol} \mathrm{frac}$ \\
Bottom Prod Frac Light Component & $R$ & 1 \\
Reflux Ratio & $a$ & 4 \\
Relative Volatility & & 1 \\
q-line & & \\
\hline
\end{tabular}

\begin{tabular}{|lll|}
\hline Calculations & & \\
Top Product Flowrate & D & $0.0286 \mathrm{kmol} \mathrm{h}^{1}$ \\
Bottom Product Flowrate & W & $0.0714 \mathrm{kmol} \mathrm{h}^{1}$ \\
Liquid Flow at Top of Column & L & 0.0286 \\
Vapour Flow in Top of Column & V & 0.0572 \\
Liquid Flow in Bottom of Column & L' & 0.1286 \\
Vapour Flow in Bottom of Column & V' & 0.0572 \\
X Coords of Op Line Intersection & qx & 0.3 \\
Number of Plates (plus Reboiler) & & 13 \\
Feed Plate (From Top of Column) & & 7 \\
Minimum Reflux Ratio (Underwood) & & 0.9422 \\
Minimum Num Theoretical Places (Fenske) & 4.2934 \\
\hline
\end{tabular}

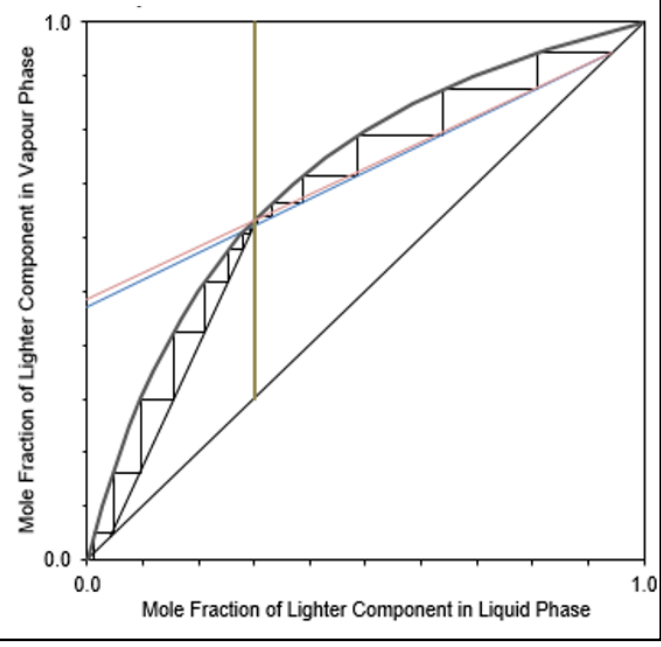

Fig. 10. Simulation results illustration using Ms. Excel in the design of the distillation column where reflux ratio $=1$ produces number of plates $=13$ based on the Mc Cabe Thiele method.

Figure 11 shows the correlations between the reflux ratio to the number of plates and the location of the feed plate. The number of plates decreases along with an increase in the reflux ratio. The decrease in the number of plates reached a constant value when the given reflux ratio exceeds 3 . This is due to the large amount of condensate returning to the column, thereby reducing the number of plates needed for separation $[9,12]$. 


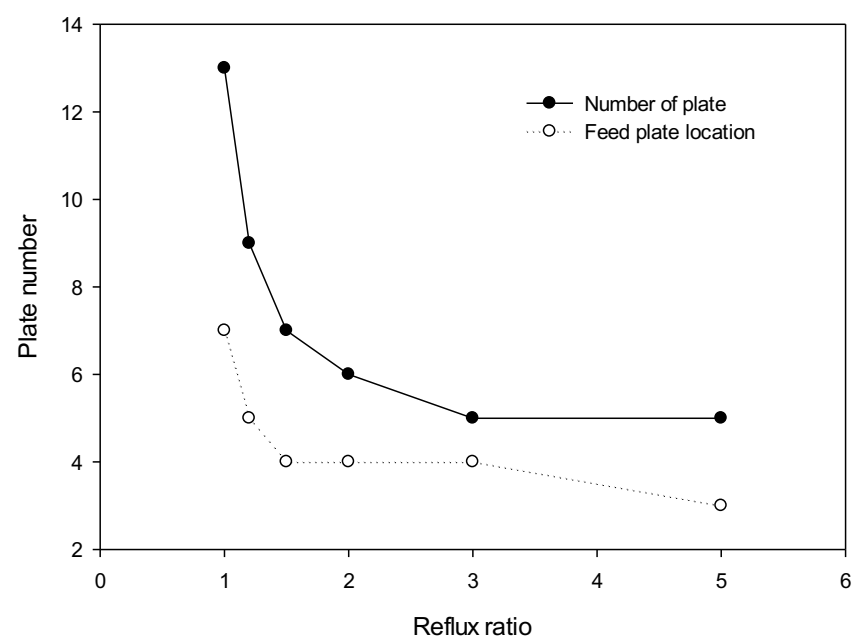

Fig. 11. Reflux ratio correlations to number of plates and feed plate location.

The relationship of reflux ratio and number of plates is shown in Figure 12, where increase in reflux ratio results in the decrease of column height caused by the decrease in the number of plates in the column. In contrast, an increase in the reflux ratio causes an increase in the distillation column diameter. This corresponds to the rate of steam affecting the diameter of the column. The rising steam flow rate will affect the column diameter to increase [13]. Meanwhile, based on the study conducted by Irawan and Nata [14], steam flow rate will increase as the number of column plates decreases.

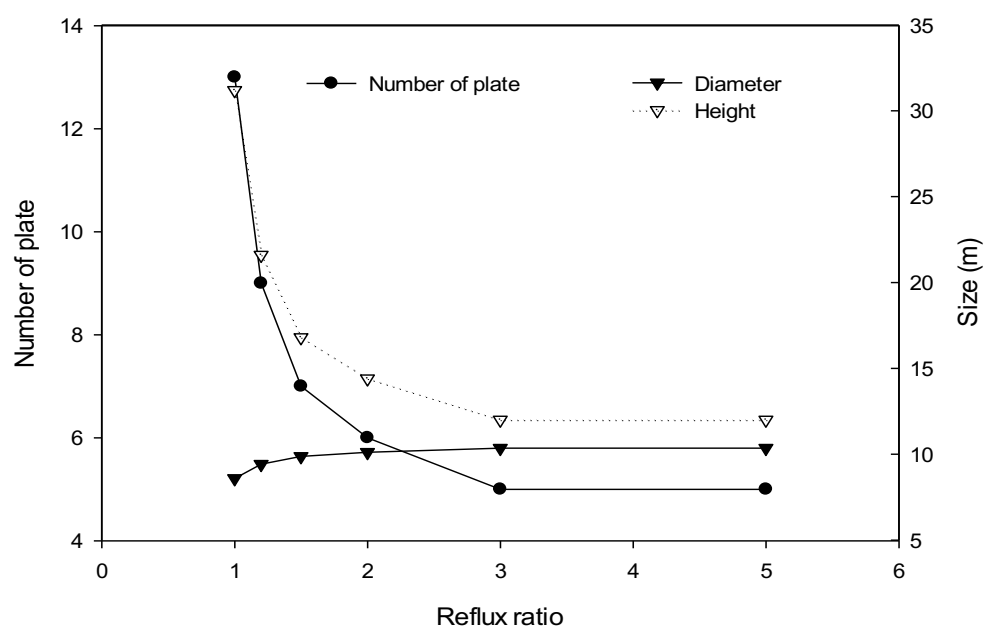

Fig. 12. Reflux ratio and number of plates correlations to column diameter and height.

Figure 13 presents that an increase in the reflux ratio and a decrease in the number of plates in the distillation column causes an increase in condenser load that plays role in condensing the distillate yield. Similar result also applies to the reboiler, where the reboiler load used to evaporate the materials at the bottom of the column also increases. The increased reflux ratio causes an increase in the steam flow rate within the column thereby increasing the loads on the condenser and reboiler [13]. However, if the reboiler and condenser loads are set at a minimum, the number of plates needed for separation will be infinite. 


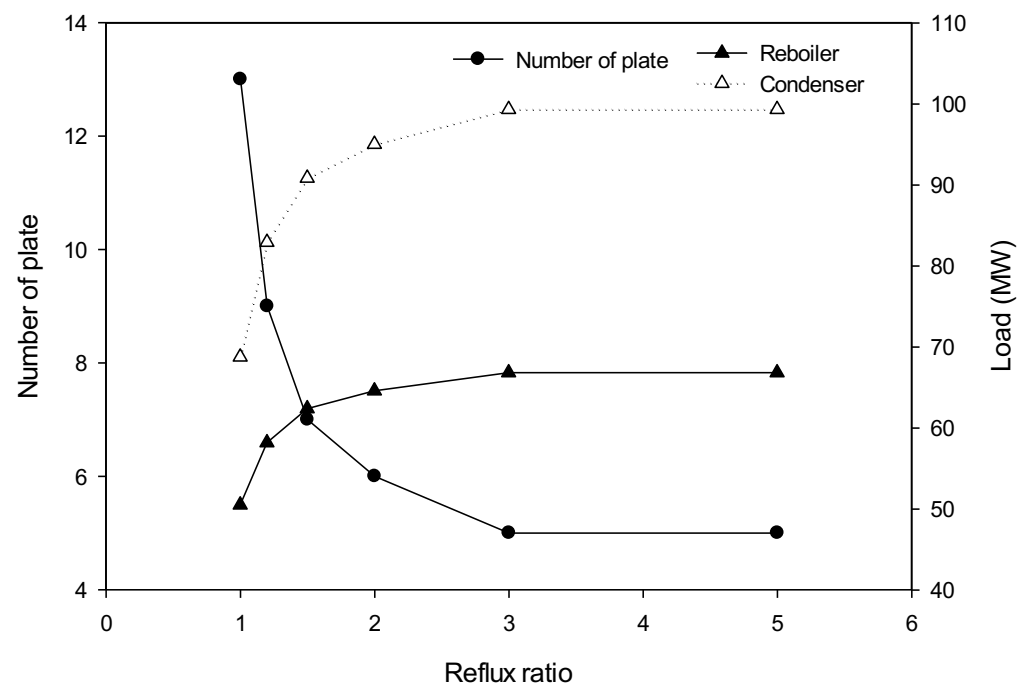

Fig 13. Relationship between reflux ratio and number of plates to the condenser and reboiler loads.

\subsection{Economic Design and Process Optimization}

\subsubsection{Basic of economic calculation}

The basis for calculating economic value applied refers to the book chapter Distillation economic optimization [15]. Distillation column economic calculation bases are shown in Table 5. The results of economic calculations of the distillation column are shown in Table 6.

Table 5. Economic foundation in calculations [16]

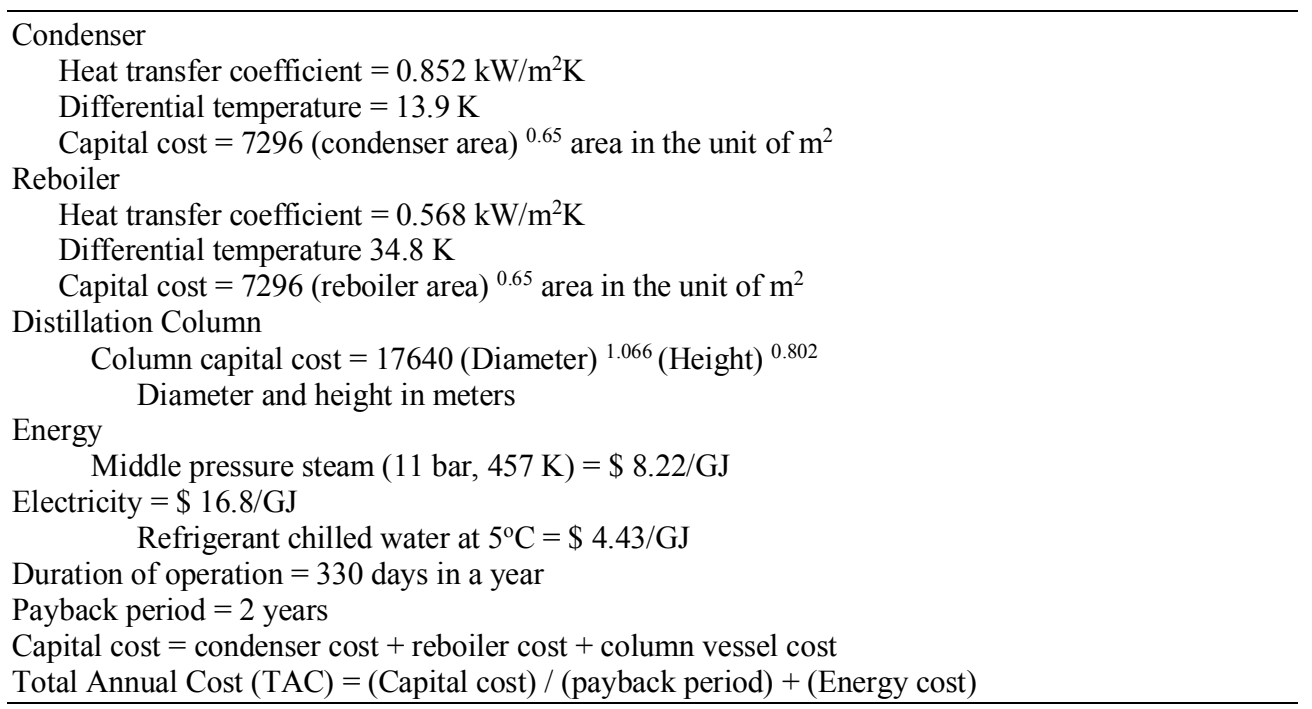


Table 6. The economic calculations results of the distillation column design.

\begin{tabular}{lrrrrrrr}
\hline \multicolumn{1}{c}{ Reflux ratio } & \multicolumn{1}{c}{$\mathbf{1}$} & \multicolumn{1}{c}{$\mathbf{1 . 2}$} & \multicolumn{1}{c}{$\mathbf{1 . 5}$} & \multicolumn{2}{c}{} & \multicolumn{1}{c}{$\mathbf{3}$} & \multicolumn{1}{c}{$\mathbf{5}$} \\
\hline Number of plates & 13 & 9 & 7 & 6 & 5 & 5 \\
Feed plate location & 7 & 5 & 4 & 4 & 4 & 3 \\
Column diameter $(\mathrm{m})$ & 8.59 & 9.42 & 9.87 & 10.11 & 10.35 & 10.35 \\
Column height $(\mathrm{m})$ & 31.20 & 21.60 & 16.80 & 14.40 & 12.00 & 12.00 \\
Condenser load $(\mathrm{MW})$ & 35.79 & 49.95 & 57.87 & 62.04 & 66.35 & 66.35 \\
Reboiler load $(\mathrm{MW})$ & 25.53 & 33.21 & 37.41 & 39.60 & 41.85 & 41.85 \\
Condenser surface area $\left(\mathrm{m}^{2}\right)$ & 302.21 & 421.78 & 488.65 & 523.86 & 560.26 & 560.26 \\
Reboiler surface area $\left(\mathrm{m}^{2}\right)$ & 129.17 & 168.02 & 189.26 & 200.34 & 211.73 & 211.73 \\
Condenser cost $\left(10^{6} \$\right)$ & 0.30 & 0.37 & 0.41 & 0.43 & 0.45 & 0.45 \\
Reboiler cost $\left(10^{6} \$\right)$ & 0.17 & 0.20 & 0.22 & 0.23 & 0.24 & 0.24 \\
Column cost $\left(10^{6} \$\right)$ & 0.67 & 0.23 & 0.19 & 0.18 & 0.16 & 0.16 \\
Capital cost $\left(10^{6} \$\right)$ & 1.14 & 0.80 & 0.82 & 0.83 & 0.84 & 0.84 \\
Total cost of energy & 0.34 & 0.45 & 0.50 & 0.53 & 0.56 & 0.56 \\
$\left(10^{6} \$\right.$ year) & 0.91 & 0.85 & 0.91 & 0.95 & 0.98 & 0.98 \\
Total Annual Cost $\left(10^{6} \$\right)$ & & & & & &
\end{tabular}

Figure 14 displays the relationship between the reflux ratio and the capital cost incurred. The capital cost for the distillation column tends to decrease with the increase in the reflux ratio. This is due to the decrease in the number of plates in the distillation column as the reflux ratio increases. Different result applies to the price of the heat exchanger which increases in cost when the reflux ratio is increased. This outcome is a result of an increase in condenser and reboiler loads when the reflux ratio is increased, whilst the total capital cost profile follows the conditions of the sum of the heat exchanger and column cost.

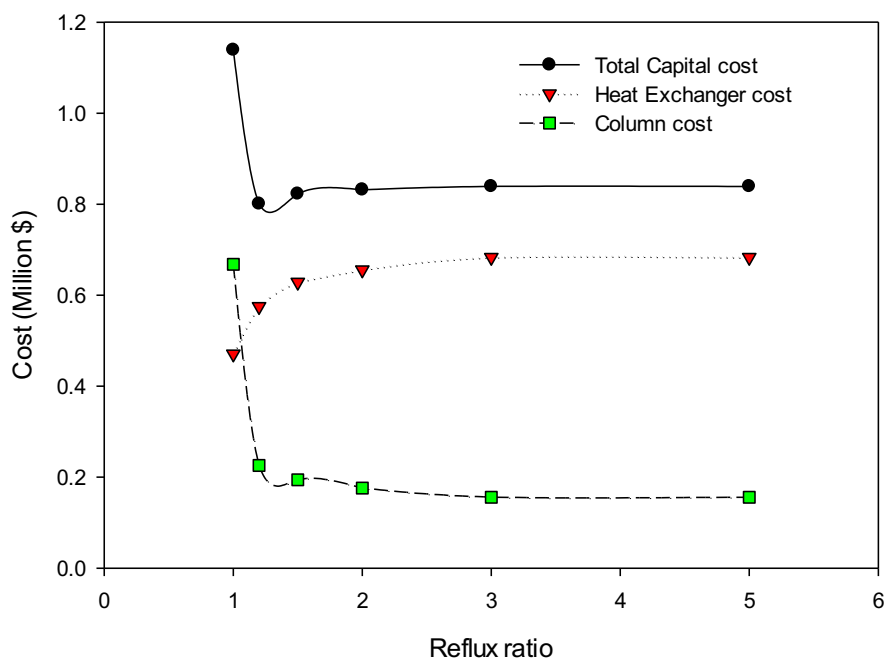

Fig. 14. Reflux ratio correlation to the capital cost.

More in-depth analysis can be done with the total annual cost (TAC) calculation method. TAC is a combination of annual energy costs and capital costs involved in constructing 
equipment. As can be seen in Figure 15, an increase in reflux ratio increases the energy cost of the distillation column. The energy costs encompass the operational costs of condensers and reboilers. Accordingly, the increase in energy costs is due to the addition of reboiler and condenser loads when the reflux ratio is increased. Moreover, TAC curve in Figure 16 presents that at reflux ratio 1.2 , a minimum value is achieved.

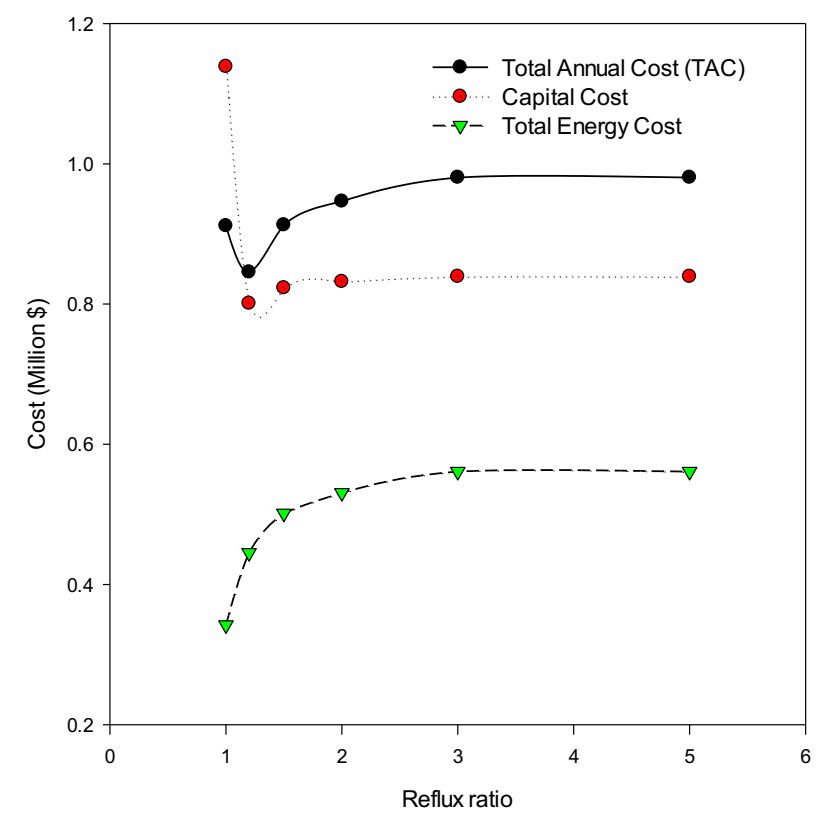

Fig. 15. Correlation between reflux comparison and profitability parameters.

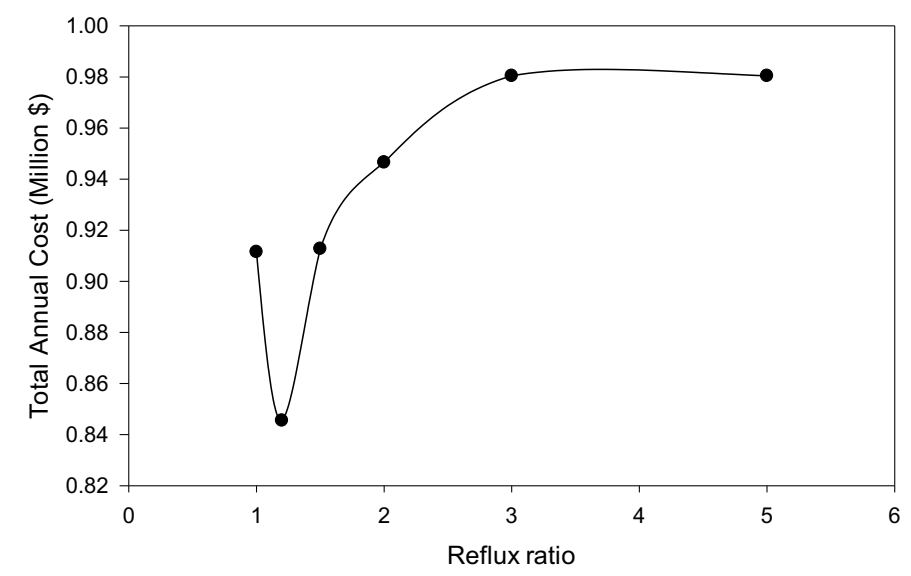

Fig. 16. Correlation between reflux ratio and total annual cost (TAC).

Decrease in TAC value only occurs at reflux ratio 1.2, beyond which increase in value occurs until a constant value is reached at reflux ratio of 3 . At reflux ratio 1.2 , the TAC calculated is $\$ 850,000$, the lowest among the values implied for other reflux ratio variation observed. On this value, it can be concluded that the optimum reflux ratio resulting the highest economic value with the reflux ratio 1.2. 


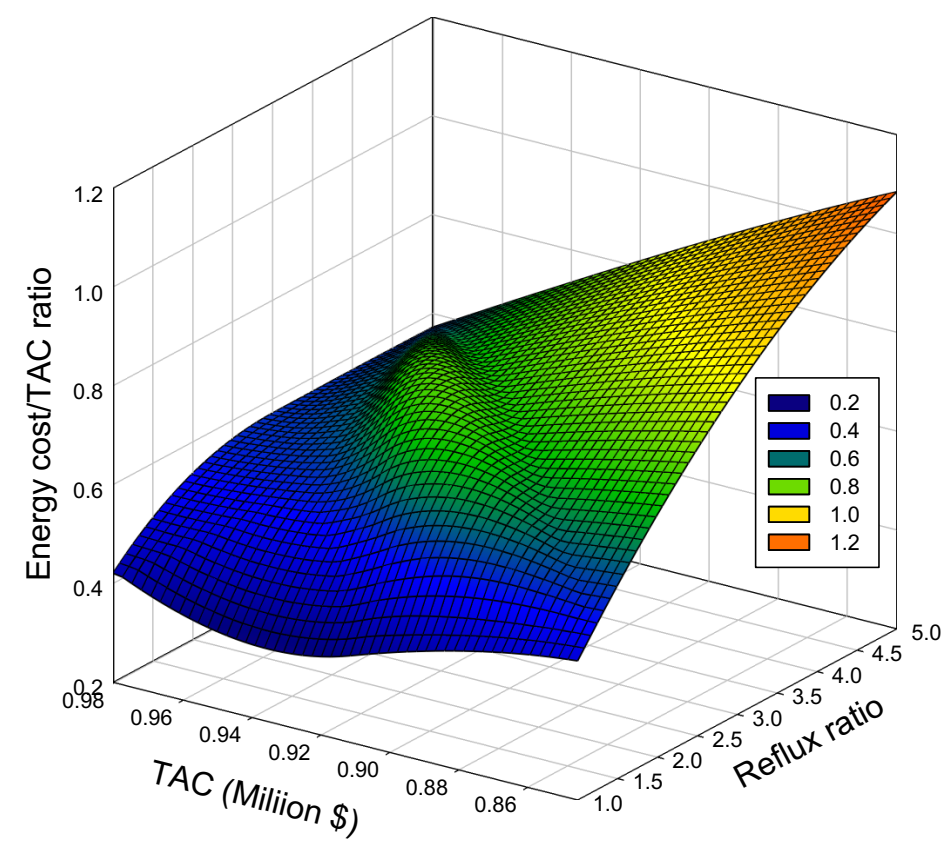

Fig. 17. Correlation between reflux ratio, total annual cost (TAC), and ratio of energy cost/TAC.

The correlation of reflux ratio, total annual cost (TAC), and the ratio of energy cost/TAC depicted in Fig 17. This figure shows the value of energy cost in TAC as the optimization parameter. If reviewed more specifically, in Fig. 17 the ratio of energy costs to TAC can be seen that the value of energy cost / TAC ratio at the optimum variable reflux ratio 1.2 is still relatively high, reaching 0.5 . This condition means that $50 \%$ of TAC is energy cost; this is undoubtedly a challenge for future studies and simulations to reduce the value of this energy cost in TAC. The approximation has been studied to decrease the energy cost that widely used by simple or complex process integration [8]. Thus, future work will be focused on the simulation and optimization of energy cost in the distillation process.

\section{Conclusion}

1. Analysis of degree of freedom using three different methods produce the same value of 1. Through the structural array analysis, the design variable determined is the value of the molar flow rate (N1) of the feed entering the distillation column.

2. The distillation column design simulation successfully provides outcomes by varying the reflux ratio values from 1 to 5 .

3. The optimum variable value is obtained at reflux ratio 1.2 with implied minimum total annual cost of $\$ 850,000$.

\section{Recommendation}

The simulation applied in the present study still uses several design assumptions. Forthcoming simulations should be conducted with less design assumptions to generate results near to the actual operating results. 


\section{References}

1. P. Luyben, Process Modelling: Simulation and Control for Chemical Engineers (McGraw-Hill, New York, 1990)

2. F. G. Shinskey, Distillation Control: For Productivity and Energy Conservation (McGraw-Hill, New York, 1984)

3. S. Enagandula S and J. B. Riggs, Control Engineering Practice 14, (2004)

4. S. Hurowitz, J. Anderson, M. Duvall, Journal of Process Control 13, (2003)

5. U. Diwekar M., K. P. Madhavan, R. E. Swaney, Ind. Eng. Chem. Res. 28, (1989)

6. J. Ren, S. Tan, L. Dong, Chemical and Process Engineering 31, (2010)

7. S. M. Mauhar, B. G. Barjaktarovic, M. N. Sovilj, Chemical Papers 58, (2004)

8. A. Fazlali, M. Hosseini M, B. Yasini, Songkonakarin Journal of Science and Technology 31, (2009)

9. H. J. Chen and Y. C. Lin, Tamking Journal of Science and Engineering 4 (2), (2001)

10. N. Ghasem and R. Henda, Principles of Chemical Engineering Processes Material and Energy Balances (CRC Press, Boca Raton, 2015)

11. D. F. Rudd and C. C. Watson, Strategy of Process Engineering (Wiley International Edition, Wisconsin, 1968)

12. A. Budiman, ASEAN Journal of Chemical Engineering 8 (1), (2008)

13. S. Steinigeweg and J. Gmehling, Distillation in the book: Green Separation Processes: Fundamentals and Applications (Wiley-VCH Verlag GmbH \& Co., 2006)

14. C. Irawan and I. F. Nata, Info Teknik 6 (1), (2005)

15. W. L. Luyben, Distillation Economic Optimization in the book: Distillation Design and Control Using Aspen ${ }^{\mathrm{TM}}$ Simulation (John Wiley \& Sons, Inc., 2013)

16. Y.C. Wu, I-Lung Chien, W. L. Luyben, Ind. Eng. Chem. Res. 48, 23, 10532-10540 (2009) 